\title{
Ciência e Religião: chega de briga!
}

O advento da Cultura Moderna trouxe uma conturbada relação entre ciência e religião. Razões existiram para tanto. A história de tal relação tem muitos aspectos e exageros de todos os lados.

Este artigo quer apontar na direção da superação do mal entendido. O espaço disponível aqui não permite entrar em detalhes, mas será suficiente para mostrar que existe um caminho pelo qual se pode conviver harmonicamente. A maior dificuldade não está na ciência e tão pouco na religião, mas em posturas arrogantes de pessoas e instituições que não conseguem conviver com a diferença e com a necessidade de mudanças.

Em cinco passos indicaremos elementos que precisam ser reconhecidos tanto por religiosos como por cientistas. Ainda há um longo caminho pela frente, porém já existem muitos trabalhos que procuram encontrar aproximações entre estes dois fenômenos da história humana.

Para simplificar usaremos o esquema de um estudioso chamado IAN G. BARBOUR, no livro Quando a Ciência Encontra a Religião - Inimigas, Estranhas ou Parceiras? Este autor aponta quatro perspectivas da relação ciência e religião: conflito, independência, diálogo, e integração. Então, ao longo dos cinco passos, faremos referência à tipologia de Barbour.

\section{Primeiro passo: Deus não é necessário.}

Quando o célebre físico STEPHEN HAWKING, em seu último livro publicado conjuntamente com Leonard Mlodinow e intitulado $O$ Grande Projeto, afirmou que Deus não é necessário para explicar a origem do universo, muitos religiosos ficaram chocados.

De fato, é possível prescindir de Deus para explicar toda evolução do universo até o aparecimento da VIDA e, partir do aparecimento da vida, explicar sua evolução sem nenhum recurso vindo de uma fonte que não se encontre na própria história natural.

Evidentemente que a ciência não nos fornece todos os detalhes do processo, mas oferece um quadro bastante razoável de evidências pelas quais se podem perceber que existe uma conexão extremamente convincente de tudo o que existe no universo observável. A física, a química e a biologia se cruzam desde a galáxia mais distante até o menor inseto enxergado pelo olho humano. Por exemplo, o elemento químico carbono existe em uma estrela, em uma pedra ou em um ser humano.

O conhecido naturalista britânico CHARLES DARWIN, depois de viajar cinco anos a bordo do navio Beagle e aprofundar por mais vinte anos sua pesquisa, publica em 1859 o livro A origem das espécies que será um marco na explicação do processo de origem da vida. Sem entrar em momento algum na controvérsia da existência ou não de Deus, ele dará ao mundo 
uma explicação que, ao longo do tempo, só encontrará aperfeiçoamentos, como no desenvolvimento da genética e a leitura do genoma humano, mas não será negada.

Ora, será que o fato de ser possível explicar a origem do universo e da vida sem recorrer a uma possível fonte não natural, elimina a escolha de um ser que daria sentido a tudo? A única escolha seria o acaso? Tudo que existe, existe por mera conjunção de fatores que se reuniram ao longo de bilhões de anos? Será que nos resta apenas uma posição de conflito, isto é, ou a ciência ou a religião? Vamos ao segundo passo.

\section{Segundo passo: Deus e a história humana.}

Sem entrar no mérito da existência ou não de Deus, é importante verificar o processo histórico pelo qual o ser humano foi colocando em sua vida uma razão de fundo para sua trajetória.

Em um dado momento do processo evolutivo (não se pode verificar exatamente quando), o ser humano tomou consciência de sua própria existência e produziu uma linguagem para comunicar tal consciência. Diferentemente de outros animais, o animal humano somou à luta pela sobrevivência mecanismos de força subjetiva. Construiu casas com determinadas formas, coloriu as casas, plantou jardim ao redor da casa, inventou canções, e começou a contar histórias ao redor da fogueira.

Certos cientistas afirmam que tudo isso não passa de um mecanismo evolutivo pelo qual o animal humano foi, por seleção natural, melhorando sua sobrevivência. Contudo, apesar da explicação evolutiva ser extremamente qualificada, nada impede que se olhe em outra direção, sem negar, obviamente, os resultados das ciências naturais.

Fato é que, do Sol ao Deus monoteísta dos judeus, cristãos e islâmicos, por exemplo, constata-se fortemente a entrada de uma força que um dos pais da sociologia, Emile Dürkheim, vai afirmar que enquanto houver sociedade, haverá religião. A religião é um mecanismo que empurra o ser humano para uma perspectiva que vai além da luta pela sobrevivência. Em um dado momento do processo, essa experiência nomeou uma razão para tanto: DEUS. As religiões monoteístas chamam esta experiência de revelação.

Assim, Deus entra na história humana quando no processo evolutivo o ser humano foi capaz de reconhecer que sua sobrevivência estava calcada não apenas em uma força física ou mesmo intelectual, mas em uma sustentação que equilibra todas as forças. Certamente que o processo é complexo, no entanto é possível verificar alguns mecanismos pelos quais a religião se apresenta como uma construção razoável.

\section{Terceiro passo: Deus e as religiões}

A cultura é uma produção especificamente humana. Cultura que significa os sentidos, valores, significados, que perpassam a vida de um povo. Nenhum grupo humano vive sem demarcar os seus sentidos e valores. 
No processo de construção cultural se pode verificar facilmente que o ser humano é um ser eminentemente simbólico. Símbolo, palavra de origem grega que significa aquilo que une, é uma espécie de mecanismo de ligação dos sentidos. No interior de tal processo a simbologia foi expressando de modo cada vez mais complexo as razões de fundo para justificar o caminho da sobrevivência. Por isso, certas experiências fundamentais foram separadas de outras. Quando acontece tal separação se constitui o sagrado. Ritos e mitos foram constituídos para expressar tal experiência. E então uma ligação simbólica foi feita: Deus é a razão maior e a religião o mecanismo que, através de uma complexa produção simbólica, contida na própria cultura, une os seres humanos a esta razão de fundo.

De novo se pode concluir que tal processo não passa de um mecanismo puramente biológico, mantendo o conflito oriundo neste caso da ciência, e não da religião. O conflito pode ser produzido pela religião, negando a ciência, ou pela ciência, negando qualquer validade da experiência religiosa. Mas será que o diálogo é impossível?

\section{Quarto passo: buscando o encontro.}

Uma posição interessante, para além do conflito, é a independência. Interessante, mas insuficiente. Esta posição defende que religião e ciência têm linguagem e objetivos diferentes, portanto, uma não deve interferir no campo da outra.

O famoso biólogo francês JACQUES MONOD, falecido em 1976, defendeu a tese chamada por ele de "duplo magistério", isto é, cada um defende com sua própria autoridade o seu objetivo. O teólogo protestante KARL BARTH, falecido em 1968, foi pelo mesmo caminho.

A questão é que tal posição é valida em algumas circunstâncias, mas não consegue dar conta de tudo. O cristianismo, por exemplo, que constituiu boa parte do seu edifício teológico em premissas platônico-aristotélicas está seriamente interrogado por uma concepção de tempo e espaço fixista, o que no contexto atual é completamente fora de propósito. O universo é dinâmico e não se pode admitir uma ruptura completa entre a vida e as circunstâncias da vida.

Por sua vez, a ciência permanecendo com uma metafísica materialista, acaba não dando conta do conjunto de significados que ultrapassam o determinismo científico. A física quântica é hoje o melhor exemplo da não possibilidade de determinismos. Talvez algum leitor ou leitora se surpreenda com a expressão "metafísica" relativa a ciência. No entanto, boa parte da filosofia da ciência hoje reconhece que quando se justifica uma afirmação por mecanismos que não estão restritos exclusivamente ao método científico, está se fazendo um metafísica, isto é, indo além da natureza.

A saída se encontra no diálogo e na integração. Um desafio ainda por ser superado se encontra a nossa frente. Mas assim como no passado, no caso do cristianismo, foi possível dialogar e integrar a filosofia grega, hoje podemos constatar elementos comuns que salvaguardam tanto a liberdade do método cientifico como a busca por razões que vão além de 
um "pessimismo cósmico", como afirma o teólogo JOHN HAUGHT na atualidade, teólogo jesuíta americano que tem se dedicado no aprofundamento desta questão.

\section{Quinto passo: Deus - um caminho de sentido}

O que nos resta? A ciência tem razão, do ponto de vista de sua metodologia, em afirmar a não possibilidade de verificar a existência de Deus ou de qualquer força externa para a origem do universo. Entretanto, a ausência de verificação não impossibilita a afirmação de um entrelaçamento realizado em todo cosmo por um Ser que está presente por dentro, de algum modo, em todo processo evolutivo. A imanência e a transcendência se misturam em um único processo. Corpo e alma não se configuram como duas instâncias separadas, como já vem afirmando há bastante tempo a antropologia teológica, mas estão unidos na trajetória de uma única vida que segue pela eternidade.

A ciência está dando oportunidade às religiões e à teologia para superarem o dualismo entre a matéria e o espírito. É verdade, é preciso insistir, que há um longo caminho pela frente. $\mathrm{Na}$ metade do século $\mathrm{XX}$, o teólogo e cientista do campo da paleontologia, TEILHARD DE CHARDIN, falecido em 1955, não conseguiu ser ouvido. Porém, cada vez mais pessoas estão percebendo que a saída para as religiões não se encontra no fundamentalismo, em afirmações literais da Bíblia, mas em uma postura que ultrapassa qualquer tentativa de absolutismo religioso.

É preciso afirmar que o núcleo fundamental das religiões não está em provar a existência de Deus, em refutar aqueles que não creem, em procurar identificar uma verdade a qualquer custo, mas em estabelecer princípios que melhorem a vida humana na terra, porque no "céu", enquanto nome simbólico da continuidade da vida, só o amor se faz necessário, como afirma o apóstolo Paulo na carta aos Coríntios:

Agora vemos em espelho e de maneira confusa, mas, depois, veremos face a face. Agora o meu conhecimento é limitado, mas depois conhecerei como sou conhecido. Agora, portanto, permanecem, fé, esperança, caridade, estas três coisas. A maior delas, porém, é a caridade. (1Cor 13,12-13)

Assim sendo, aqueles que creem optam por uma experiência de sentido. Uma opção que não exclui pensar, duvidar, criticar. Um sentido que não deve estar em contraposição ao processo de construção do conhecimento humano. Por outro lado, o conhecimento humano, representado pelas ciências naturais, não precisa excluir a religião para se afirmar na sociedade. Estamos todos de acordo, e aqui se pode incluir dois cientistas que não creem (E. WILSON E MARCELO GLEISER, por exemplo), que o planeta terra é a casa de religiosos e ateus, portanto como diria MARTIN LUTHER KING, "Temos de aprender a viver juntos como irmãos ou perecemos juntos como loucos". 


\section{Para refletir:}

- Que tipo de relação pode existir entre ciência e religião?

- Diante da relação entre ciência e religião diagnosticada no artigo, como pensar e desenvolver a experiência religiosa nos tempos atuais?

\section{Bibliografia:}

BARBOUR, Ian G. Quando a Ciência Encontra a Religião: Inimigas Estranhas ou Parceiras? São Paulo: Cultriz, 2004.

HAWKING, S. \& MLODINOW L. O Grande Projeto. Rio de Janeiro: Nova Fronteira, 2011. HAUGHT, J. F. Deus após Darwin - Uma Teologia Evolucionista. 2ª ed., Rio de Janeiro: José Olympio Editora.

GLEISER, M. Criação Imperfeita - Cosmo, Vida e o Código Oculto da Natureza. 3ª ed., Rio de Janeiro / São Paulo: Record, 2010.

CARIAS, C. P. O futuro que se abre ao presente em evolução: encontro entre teologia e teoria da evolução no discurso escatológico, in RUBIO, A. G. \& AMADO, J. P. "Fé Cristã e pensamento evolucionista - Aproximações teológico-pastorais a um tema desafiador. São Paulo: Paulinas, 2012. 